\title{
Effect of N,C-ITO on Composite N,C-TiO $/$ /N,C-ITO/ITO Electrode Used for Photoelectrochemical Degradation of Aqueous Pollutant with Simultaneous Hydrogen Production
}

\author{
Kee-Rong Wu, ${ }^{1}$ Chung-Hsuang Hung, ${ }^{2}$ Chung-Wei Yeh, ${ }^{3}$ Chien-Chung Wang, ${ }^{1}$ \\ and Jiing-Kae $\mathrm{Wu}^{1}$ \\ ${ }^{1}$ Department of Marine Engineering, National Kaohsiung Marine University, Kaohsiung 811, Taiwan \\ ${ }^{2}$ Department of Safety, Health and Environmental Engineering, National Kaohsiung First University of Science and Technology, \\ Kaohsiung 811, Taiwan \\ ${ }^{3}$ Department of Information System, Kao Yuan University, Kaohsiung 811, Taiwan
}

Correspondence should be addressed to Kee-Rong Wu, krwu@mail.nkmu.edu.tw

Received 15 September 2011; Revised 11 November 2011; Accepted 11 November 2011

Academic Editor: Jiaguo Yu

Copyright ( $) 2012$ Kee-Rong Wu et al. This is an open access article distributed under the Creative Commons Attribution License, which permits unrestricted use, distribution, and reproduction in any medium, provided the original work is properly cited.

\begin{abstract}
This study reports the effect of N,C-ITO (indium tin oxide) layer on composite N,C-TiO $2 / \mathrm{N}, \mathrm{C}-\mathrm{ITO} / \mathrm{ITO}$ (Ti/TO) electrode used for efficient photoelectrocatalytic (PEC) degradation of aqueous pollutant with simultaneous hydrogen production. The structural properties of the composite Ti/TO electrode that determined by X-ray diffraction and Raman scattering, show primarily the crystallized anatase $\mathrm{TiO}_{2}$ phase and distinct diffraction patterns of polycrystalline $\mathrm{In}_{2} \mathrm{O}_{3}$ phase. Under solar light illumination, the composite Ti/TO electrode yields simultaneously a hydrogen production rate of $12.0 \mu \mathrm{mol} \mathrm{cm} \mathrm{cm}^{-1} \mathrm{~h}^{-1}$ and degradation rate constant of $12.6 \times 10^{-3} \mathrm{~cm}^{-2} \mathrm{~h}^{-1}$ in organic pollutant. It implies that the overlaid $\mathrm{N}, \mathrm{C}-\mathrm{TiO}_{2}$ layer enhances not only the photocurrent response of the composite Ti/TO electrode at entire applied potentials, but also the flat band potential; a shift of about $0.1 \mathrm{~V}$ toward cathode, which is desperately beneficial in the PEC process. In light of the X-ray photoelectron spectroscopy findings, these results are attributable partly to the synergetic effect of $\mathrm{N}, \mathrm{C}$-codoping into the $\mathrm{TiO}_{2}$ and ITO lattices on their band gap narrowing and photosensitizing as well. Thus, the Ti/TO electrode can potentially serve an efficient PEC electrode for simultaneous pollutant degradation and hydrogen production.
\end{abstract}

\section{Introduction}

The photoelectrocatalytic (PEC) splitting of water using solar energy has attracted substantial attention as a means of producing hydrogen as a clean and renewable resource [1-3]. Researchers have sought suitable photocatalysts of the splitting of water since a pioneering work of Fujishima and Honda by employing titanium dioxide $\left(\mathrm{TiO}_{2}\right)$ semiconductor as photoanode in 1972 [4]. As an anatase $\mathrm{TiO}_{2}$ photoanode is excited by incident light with wavelengths shorter than $387 \mathrm{~nm}$, electrons and holes can be generated. In short, the photogenerated holes oxidize and decompose water, even some organic or inorganic substances in aqueous solution, at the photoanode while the electrons can interact with hydrogen ions into hydrogen at the counter platinum
$(\mathrm{Pt})$ electrode. It has been shown that hydrogen production can be enhanced by irradiating $\mathrm{Pt} / \mathrm{TiO}_{2}$ suspensions with simultaneous degradation of azo dyes [5]. Moreover, photoelectrolytic cleavage of biomass wastes, such as urine, ethanol and glycerol, in water is much more efficient for electricity generation [6] and hydrogen production [7-9].

For efficient PEC splitting of water, the n-type photoanode is required to have narrow band gap around $2.0 \mathrm{eV}$, suitable negative flat band potential, good stability and high quantum efficiency [10]. Among various semiconductor photocatalysts, $\mathrm{TiO}_{2}$ is one of the most popular catalysts because it is environmentally friendly and chemically stable in electrolyte solution with high quantum efficiency. However, the use of $\mathrm{TiO}_{2}$ is limited by its wide band gap $(\sim 3.2 \mathrm{eV})$. Alternatively, semiconductors with smaller 
band gaps, such as $\mathrm{CdS}(2.4 \mathrm{eV}), \mathrm{Fe}_{2} \mathrm{O}_{3}(2.3 \mathrm{eV})$, and $\mathrm{Cu}_{2} \mathrm{O}(2.2 \mathrm{eV})$, commonly suffer from photocorrosion in electrolyte solution and fast recombination of the photogenerated carriers [10-13]. It is well known that metal or semiconductor with a high work function coupled with other semiconductor can significantly enhance the oxidation ability of photogenerated holes in the semiconductor, due to efficient carrier separation. A heterostructured film, such as $\mathrm{TiO}_{2} / \mathrm{ITO}$ (indium tin oxide), $\mathrm{TiO}_{2} / \mathrm{WO}_{3}, \mathrm{CdS} / \mathrm{TiO}_{2}$ or $\mathrm{TiO}_{2} / \mathrm{SnO}_{2}$, has been proposed for providing a potential driving force for photogenerated charge carrier separation [14-18]. Dai et al. have demonstrated that the superior photocatalytic reactions of the $\mathrm{TiO}_{2} / \mathrm{ITO}$ film are mostly associated with the photogenerated holes because ITO has a higher work function $(\sim 4.7 \mathrm{eV})$ [19] than $\mathrm{TiO}_{2}$ and a Schottky barrier can form at the $\mathrm{TiO}_{2} / \mathrm{ITO}$ interface, where the ITO thin film accepts electrons [16]. One should note that both the proximity of their conduction band to conduction band [20] and the proper redox positions of heterostructure play significant roles on charge carrier transfer and thus photocatalysis in the heterostructured film.

Photocatalysis is well known to be a very useful technique in various environmental applications for degrading a wide range of contaminants in air or water. $\mathrm{TiO}_{2}$ is one of the most suitable semiconductors for several environmental applications, including air purification, water disinfection and hazardous waste remediation [21-23]. $\mathrm{TiO}_{2}$ codoped with anionic species, such as carbon $(\mathrm{C})$ and nitrogen $(\mathrm{N})$, appears to have very promising visible-light photocatalytic properties in NO oxidation, methylene blue (MB) degradation, and Escherichia coli disinfection [24-27]. Yin et al. have shown that substitution of the $\mathrm{O}$ sites by $\mathrm{N}$ and $\mathrm{C}$ is responsible for visible-light photocatalytic activities [27]. It has been found that the $\mathrm{N}, \mathrm{C}-\mathrm{TiO}_{2}$ films prepared at low doping concentrations of $\mathrm{N}(1.3 \%)$ and $\mathrm{C}(1.8 \%)$ have exhibited superior photocatalytic degradation of $\mathrm{MB}$ solution [28]. Moreover, $\mathrm{TiO}_{2-x} \mathrm{~N}_{x}$ catalyst with a low doping concentration $(x=0.021)$ has shown the highest activity for the 4-chlorophenol decomposition under the visible-light irradiation $[29,30]$. On the other hand, both $\mathrm{N}$-doped $\mathrm{In}_{2} \mathrm{O}_{3}$ [31] and ITO (N-ITO) [32] and C-doped $\mathrm{In}_{2} \mathrm{O}_{3}$ [33] electrodes were demonstrated to be promising photocatalysts with favorable PEC properties, especially under visible light $(\lambda>378 \mathrm{~nm})$. However, both ITO and $\mathrm{N}$ ITO films exhibit no photocatalytic activity in degradation of MB solution [32], though photocatalytic degradation of azo dyes has been reported active [34]. We previously found that an applied potential could serve as a highly efficient way to suppress hole-electron recombination of the N-ITO electrode, where the generated photocurrent density sharply increased with its applied potential. This was ascribed mostly to better electrical conductivity [31] and proper positions of the flat band potentials [35] as a result of suppression of $\mathrm{InN}$ and $\mathrm{SnO}_{2}$ phases in the domain-structured N-ITO electrode which was prepared at a low $\mathrm{N}$-doping content [32]. However, the origin of visible-light ability of the N-ITO films has not been exploited yet. To enhance the visible-light PEC response, the heterostructured $\mathrm{TiO}_{2} / \mathrm{ITO}$ electrodes were codoped with $\mathrm{N}$ and $\mathrm{C}$ ions grown on ITO glass substrate, as a layered composite $\mathrm{N}, \mathrm{C}-\mathrm{TiO}_{2} / \mathrm{N}, \mathrm{C}$-ITO/ITO electrode ( $\mathrm{Ti} / \mathrm{TO})$, for better durability and charge carriers transfer and thus PEC capability [36].

Dimethyl sulfoxide (DMSO) is one of the most common phenol-free organic solvents applied in semiconductor manufacturing industries due to its superior solvent property and water miscibility. However, DMSO is unable to be removed effectively by most typical biological wastewater treatment units [37]. The biodegradation of DMSO might cause the formation of some volatile and noxious compounds such as dimethylsulfide, methylmercaptan and hydrogen sulfide, causing another pollution problem [38]. Since that DMSO is also an effective radical scavenger for hydroxyl radicals $(\bullet \mathrm{OH})$, the wastewater treatment processes that can produce high-concentration $\bullet \mathrm{OH}$ radicals will be candidate processes for DMSO removal. Accordingly, some advanced oxidation processes (AOPs) such as $\mathrm{H}_{2} \mathrm{O}_{2} / \mathrm{UV}$ [39], $\mathrm{O}_{3} / \mathrm{UV}$ [40], corona discharge [41], or $\mathrm{UV} / \mathrm{TiO}_{2}$-based photocatalysts [42] are being developed for the particular purpose of reducing the DMSO concentration in the wastewater. In this study, we aim at the characterization of $\mathrm{N}, \mathrm{C}-\mathrm{TiO}_{2} / \mathrm{ITO}$ electrode with emphasis on the role of the intercalated N,CITO layer for PEC degradation of DMSO aqueous pollutant with simultaneous hydrogen production.

\section{Experimental Procedure}

An in-house closed-field unbalanced magnetron sputtering system (MIRDC, Taiwan) was used to prepare the samples. This system has four vertical magnetron targets each of dimensions $300 \times 110 \times 10 \mathrm{~mm}$. $\mathrm{TiO}_{2} / \mathrm{ITO}$ film electrodes were codoped with $\mathrm{N}$ and $\mathrm{C}$ ions on as-received ITO $(17 \Omega / s q$. and $100 \pm 10 \mathrm{~nm}$ thick) glass substrates. In short, a N,C-ITO film was initially deposited onto an unheated rotating substrate using ITO and graphite targets, on one side of the chamber. After the intercalated N,C-ITO film was completed, the substrate holder was rotated toward a pair of titanium targets (99.5\% purity) without opening the chamber for the successive deposition of $\mathrm{N}, \mathrm{C}-\mathrm{TiO}_{2}$ layer. This heterostructured composite $\mathrm{N}, \mathrm{C}-\mathrm{TiO}_{2} / \mathrm{N}, \mathrm{C}$-ITO/ITO electrode was denoted as Ti/TO. Meanwhile, two other types of $\mathrm{N}, \mathrm{C}-\mathrm{TiO}_{2} / \mathrm{ITO}$ and N,C-ITO/ITO film electrodes, denoted as $\mathrm{N}, \mathrm{C}-\mathrm{TiO}_{2}$ and $\mathrm{N}, \mathrm{C}-\mathrm{ITO}$, respectively, were prepared for comparison. All other sputtering parameters were held constant where the $\mathrm{O}_{2}$ and $\mathrm{N}_{2}$ gas proportion was kept at a low rate of $9 \%$ in an $\mathrm{Ar} / \mathrm{O}_{2} / \mathrm{N}_{2}$ gas mixture, which had a total flow rate of $55 \mathrm{sccm}$. Details of the $\mathrm{N}, \mathrm{C}-\mathrm{TiO}_{2}$ films, which were prepared at low doping concentrations of $\mathrm{N}$ and $\mathrm{C}$ were presented elsewhere [28, 32]. An as-received ITO electrode with a thickness of $300 \mathrm{~nm}$ was used for comparison. Table 1 presents the physical, morphological, and microstructural properties of the samples.

The crystal structures of the samples were analyzed using a high-resolution X-ray diffractometer (XRD, Rigaku ATXE) and Micro-PL/Raman spectroscope (Jobin-Yvon T64000). The surface topography of each sample was analyzed using an atomic force microscope (AFM, SPI $3800 \mathrm{~N}$, Seiko) with a scan resolution of $512 \times 512$ pixels. The microstructure and 
TABLE 1: Physical and microstructural properties of samples along with their $\mathrm{H}_{2}$ yield rates in $4.0 \mathrm{~N} \mathrm{Na}_{2} \mathrm{CO}_{3}$ solution under irradiation of AM 1.0 simulated solar light and $1.5 \mathrm{~V}$ applied bias.

\begin{tabular}{|c|c|c|c|c|c|}
\hline \multirow{2}{*}{ Sample } & \multirow{2}{*}{$\begin{array}{l}\text { Thickness of } \\
\mathrm{TiO}_{2} \text { : ITO, nm }\end{array}$} & \multicolumn{2}{|c|}{$\mathrm{XRD}$ intensity ratio } & \multirow{2}{*}{ RMS, nm } & \multirow{2}{*}{$\begin{array}{l}\mathrm{H}_{2} \text { yield rate, } \\
\mu \mathrm{mol} \mathrm{cm}{ }^{-2} \mathrm{~h}^{-1}\end{array}$} \\
\hline & & $(400) /(222)$ & $(440) /(222)$ & & \\
\hline N,C-ITO & $-: 1.4$ & 12.15 & 4.51 & 16.3 & 24.6 \\
\hline $\mathrm{N}, \mathrm{C}-\mathrm{TiO}_{2}$ & $2.1:-$ & 0.97 & 0.77 & 18.5 & 25.0 \\
\hline $\mathrm{Ti} / \mathrm{TO}$ & $0.4: 1.4$ & 38.53 & 5.93 & 33.6 & 28.8 \\
\hline ITO & -: 0.3 & 0.99 & 0.65 & $<2.0$ & 一 \\
\hline
\end{tabular}

thickness of the films were investigated by a scanning electron microscope (SEM, JEOL JSM-6700F). The X-ray photoelectron spectroscopy (XPS) analysis was carried out with a high-resolution X-ray photoelectron spectrometer (ULVACPHI Quantera SXM/Auger AES 650). Optical absorption of the samples was measured with respect to air using a UV spectrophotometer (Hitachi UV-2900).

PEC oxidation tests were performed using a standard PEC three-cell system that included a sample anode, a saturated calomel electrode (SCE) as a reference electrode and a $\mathrm{Pt}$ wire counter electrode $2.0 \mathrm{M} \mathrm{Na}_{2} \mathrm{CO}_{3}$ solution, ( $\mathrm{pH} \sim 11)$. The initial concentration of DMSO was $0.03 \mathrm{M}$. The DMSO residual concentration was monitored by a gas chromatography (GC, HP4890) with flame ionization detection (FID) as its detector. The analytic conditions of the GC/FID for DMSO quantification were capillary separation column (60-m long $\times 0.53 \mathrm{~mm}, 5 \mu \mathrm{m}$, VOCOL, Supelco Co.), temperature ramping from $100^{\circ} \mathrm{C}$ up to $220^{\circ} \mathrm{C}$, and detector temperature was set at $250^{\circ} \mathrm{C}$. The system was controlled by a potentiostat (CHI 610C). The samples were illuminated by artificial sunlight (Newport $96000150 \mathrm{~W}$ solar simulator) with a light intensity of Air Mass (AM) $1.0\left(75 \mathrm{~mW} \mathrm{~cm}^{-2}\right)$.

\section{Results and Discussion}

3.1. Microstructural, Morphological, and Optical Properties. Figure 1 presents the XRD patterns of all three samples along with ITO substrate, which shows distinct diffraction patterns of polycrystalline $\mathrm{In}_{2} \mathrm{O}_{3}$ phase [36]. All ITO preferred planes revealed in the $\mathrm{N}, \mathrm{C}-\mathrm{TiO}_{2}$ are about the same characteristics as in the ITO electrode. However, N,C-ITO and Ti/TO samples exhibit a significantly different pattern against the ITO substrate; the former two exhibit relatively large intensity ratios of $(400) /(222)$ and $(440) /(222)$ planes, as listed in Table 1 , which are associated with the increase in resistivity of the host ITO. The increase in resistance of conducting ITO substrate has been correlated to the decrease in fill factor of dye-sensitized $\mathrm{TiO}_{2}$ solar cells [43]. The intensity ratio that is mostly ascribed to the $\mathrm{N}$ dopant increases with its concentration in the ITO lattice [32]. This implies that the intensity ratio, namely, resistivity, can be suppressed by doping fewer amount of $\mathrm{N}$ with $\mathrm{C}$ ions into the host ITO. In addition, a phase separation of small $\mathrm{SnO}_{2}$ particles in the host crystalline ITO lattice may occur, since tin is liable to be segregated close to the surface of the lattice or along its grain boundaries under elevated deposition or posttreatment

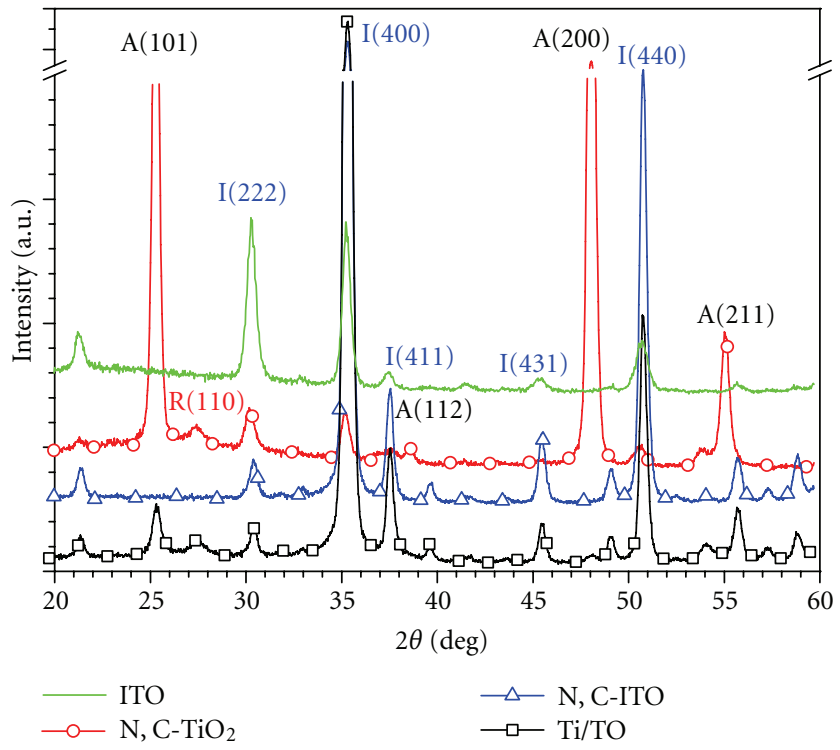

FIgURE 1: XRD patterns of the composite Ti/TO electrode along with $\mathrm{N}, \mathrm{C}-\mathrm{TiO}_{2}, \mathrm{~N}, \mathrm{C}-\mathrm{ITO}$, and ITO film electrodes, where A, R, and I stand for anatase, rutile, and ITO phase, respectively.

conditions $[44,45]$. This can cause the increase in resistivity of the N,C-ITO films. The segregation of $\mathrm{SnO}_{2}$ particles can be further examined by Raman scattering spectra in the following section.

Raman spectra are known to be very sensitive to local crystallinity and microstructures near the film surface. The Raman spectra shown in Figure 2 reveal a typical pattern of the anatase $\mathrm{TiO}_{2}$ phase for both $\mathrm{N}, \mathrm{C}-\mathrm{TiO}{ }_{2}$ and $\mathrm{Ti} / \mathrm{TO}$ samples [36]. The most intense Raman peaks of the two samples are in the range of $144 \pm 0.5 \mathrm{~cm}^{-1}$, which implies well-crystallized nature of the anatase $\mathrm{TiO}_{2}$ phase [46]. A broad peak around $235 \mathrm{~cm}^{-1}$ of $\mathrm{SnO}_{2}$ phase is observed in sample N,C-ITO. The same broad peak with very weak intensity is also observed in Ti/TO sample, as shown in the inset of Figure 2. This confirms the finding that a little $\mathrm{SnO}_{2}$ phase is segregated from the host ITO lattice, as discussed in the XRD patterns in Figure 1.

Figure 3 displays representative SEM surface morphologies of the N,C-ITO, Ti/TO and $\mathrm{N}, \mathrm{C}-\mathrm{TiO}_{2}$ along with ITO substrate. The N,C-ITO film reveals various shapes and sizes of prismatic grains $(50-200 \mathrm{~nm})$ with few small 


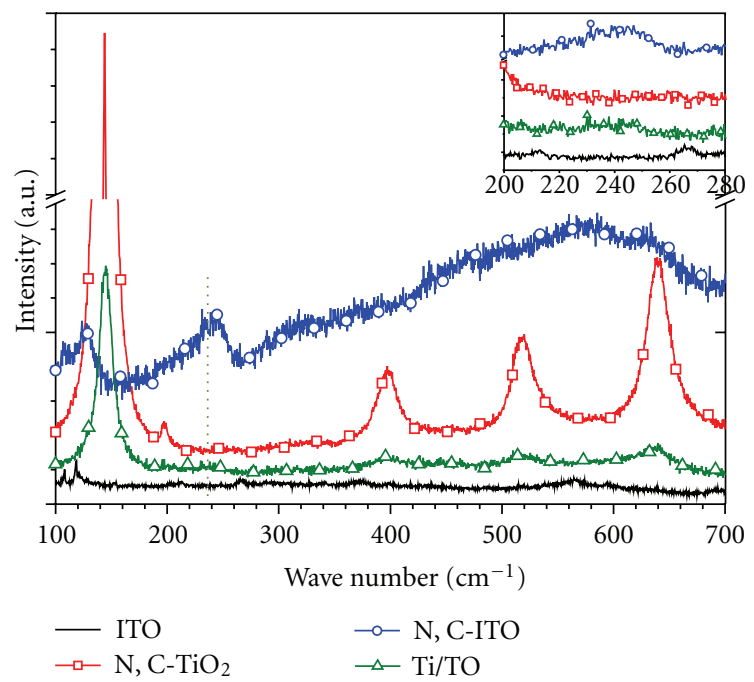

FIgUre 2: Raman spectra of the composite Ti/TO electrode along with $\mathrm{N}, \mathrm{C}-\mathrm{TiO}_{2}, \mathrm{~N}, \mathrm{C}-\mathrm{ITO}$, and ITO film electrodes.

subgrains oriented in the same direction on the surface of the film, as shown in Figure 3(a). This grain-subgrain structure is commonly found in typical DC-sputtered ITO film in Figure 3(b) [44] and on N-ITO films prepared at an optimal $\mathrm{N}$ content [32]. This implies that the N,C-ITO film still preserves a relatively low resistance. As presented in Figure 3(c), the columnar film morphology observed on the $\mathrm{Ti} / \mathrm{TO}$ is more distinct in comparison with that on the N,C$\mathrm{TiO}_{2}$ in Figure 3(d). The AFM measurements also indicate that the N,C-ITO has the RMS roughness of $16.3 \mathrm{~nm}$, where the $\mathrm{N}, \mathrm{C}-\mathrm{TiO}_{2}$ has the value of $18.5 \mathrm{~nm}$. The composite Ti/TO electrode is of the highest RMS of $33.6 \mathrm{~nm}$, as shown in Table 1. One can expect that a significant increase in surface morphology rends more reactive surface area of the sample.

Figure 4 shows the absorption spectra of four samples. Both the UV light absorbing absorption and absorption edge are enhanced for the Ti/TO as a result of the synergetic effect of two film components, as compared to that of the N,CITO or $\mathrm{N}, \mathrm{C}-\mathrm{TiO}_{2}$ alone. The band gap energy of the Ti/TO electrode is estimated to be about $2.75 \mathrm{eV}$ while the ITO substrate is reportedly of a large band gap energy of $\sim 3.8 \mathrm{eV}$. Notably, the N,C-ITO and N,C- $\mathrm{TiO}_{2}$ have barely the same value of $2.98 \mathrm{eV}$, but the UV absorption of the former is stronger than that of the latter. This implies that the Ti/TO electrode benefits an enhanced absorbing capability in the UV regions from being supported on the N,C-ITO instead of pure ITO substrate.

3.2. XPS Spectra Analysis. After in situ $\mathrm{Ar}^{+}$etching for a depth of $5 \mathrm{~nm}$, the C1s, In $3 d, \mathrm{Sn} 3 d, \mathrm{~N} 1 s$, and O1s core levels on the ITO and N,C-ITO film electrode were measured by high-resolution XPS (step size $=0.01 \mathrm{eV}$ ) in order to examine the effect of carbon and nitrogen dopants on the Ti/TO electrode. The binding energies were calibrated using the C1s energy of $284.6 \mathrm{eV}$. As shown in Figure 5(a), an intensive C1s peak is observed in the N,C-ITO, but a very weak peak is noticed in the ITO. The former is mostly attributed to free graphitic nature $(\mathrm{C}-\mathrm{C})$ and is regarded as a photosensitizer [47], whereas the latter is the result of $\mathrm{Ar}^{+}$etching off the adventitious carbon on the air-exposed ITO surface. No other noticeable XPS peak can be found in the N,C-ITO within the narrow scan range (i.e., 280$292 \mathrm{eV}$ ). This implies that the sputtered carbons did not substitute the lattice oxygen atoms to form the In-C or Sn-C bond. This is because a relatively low carbon concentration is used during the film deposition. Moreover, the O1s XPS spectra of the ITO film in Figure 5(b) were resolved into two peaks; one, at $530.6 \mathrm{eV}$, is probably due to oxygen in hydroxyl $(\mathrm{OH})$ groups; the other, at $529.8 \mathrm{eV}$, is assigned to the $\mathrm{In}-\mathrm{O}$ and $\mathrm{Sn}-\mathrm{O}$ bonds in crystalline $\mathrm{In}_{2} \mathrm{O}_{3}$ and $\mathrm{SnO}_{2}$, respectively [31]. The N,C-ITO shows a shift to lower binding energy $(529.65 \mathrm{eV})$ for the $\mathrm{O} 1 s$ peak of the crystalline $\mathrm{In}_{2} \mathrm{O}_{3}$ and $\mathrm{SnO}_{2}$. This shift is in good agreement with the results found for substitutional $\mathrm{N}$-doped $\mathrm{TiO}_{2}$ and $\mathrm{In}_{2} \mathrm{O}_{3}$ and $\mathrm{C}$-doped $\mathrm{In}_{2} \mathrm{O}_{3}[31,33]$.

The N1s XPS spectra show only a weakened peak at around $396 \mathrm{eV}$ in the N,C-ITO and no such peak is found in the ITO film (see Figure 5(c)). The best fitting of the N1s XPS spectra was obtained at a binding energy of $395.9 \mathrm{eV}$. No such peaks at $398 \mathrm{eV}$ and $400 \mathrm{eV}$ were found due to a relatively low nitrogen concentration used the electrode deposition [48]. Thus, the N1s XPS peak at $395.9 \mathrm{eV}$ that results from the substitution of the oxygen sites by nitrogen ions is highly responsible for the visible-light photocatalytic activity [49], whereas the $\mathrm{C} 1 s$ peak at $284.6 \mathrm{eV}$ of the graphite source is regarded as a photosensitizer.

As seen in Figure 5(d), the core level of In $3 d$ of the N,CITO sample shows a small shift to a lower binding energy, as compared with that of the ITO film. After curve fitting using Gaussian distribution functions, the In3d XPS peak appears only at $444.1 \mathrm{eV}$ with a full width at half maximum (FWHM) of $1.4 \mathrm{eV}$, which is very close to a value of $444.4 \mathrm{eV}$ of the ITO sample and the reported value of $444.2 \mathrm{eV}$ of crystalline $\mathrm{In}_{2} \mathrm{O}_{3}$ in the literature [50]. The formation of InN phase can be ruled out since no other In $3 d$ XPS peak at $442.4 \mathrm{eV}$ can be rationally deconvoluted from the spectra of the N,CITO. A little lower binding energy shift suggests that Nsubstitution could hardly modify the electronic interaction of indium with the oxygen anions under our sputtering conditions.

Alternatively, two peaks, $8.5 \mathrm{eV}$ apart, due to $\mathrm{Sn} 3 d_{3 / 2}$ and $\operatorname{Sn} 3 d_{5 / 2}$ XPS peaks, are observed in Figure 5(e). The best fitting for the ITO sample was achieved with two components at binding energies of 486.1 and $487.1 \mathrm{eV}$ (figure not shown). The first peak is assigned to $\mathrm{SnO}$ and the second to $\mathrm{SnO}_{2}$ [50]. However, these two components shifted to lower binding energies of 485.8 and $486.7 \mathrm{eV}$ for the N,CITO. A shift to a lower binding energy implies that the creation of $\mathrm{SnN}(486.2 \mathrm{eV})$ may not occur in the N,C-ITO [51]. Thus, the formation of $\mathrm{SnN}$ phase can be ruled out. Instead, this binding energy shift suggests a reduction of the Sn cation valence state due to a substitutional cationic doping. When $\mathrm{N}$ replaces $\mathrm{O}$, the valence state of $\mathrm{Sn}^{4+}$ is reduced to $\mathrm{Sn}^{2+}$, causing the binding energy of the $\mathrm{Sn} 3 d_{5 / 2}$ 


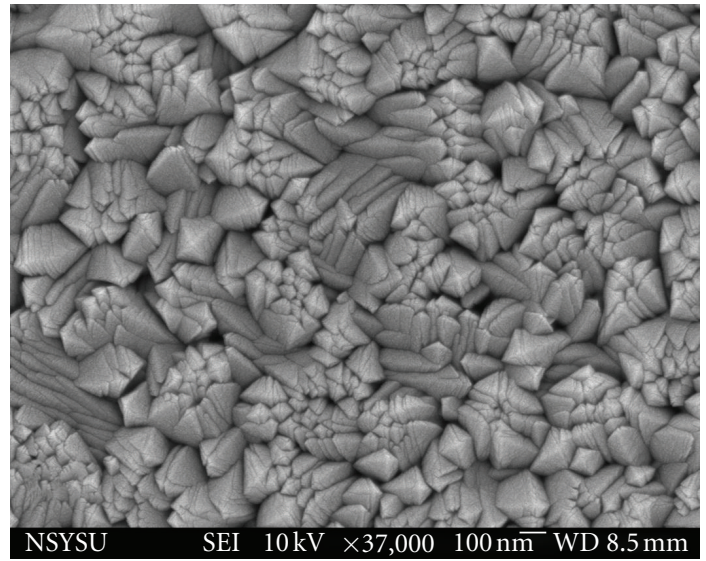

(a)

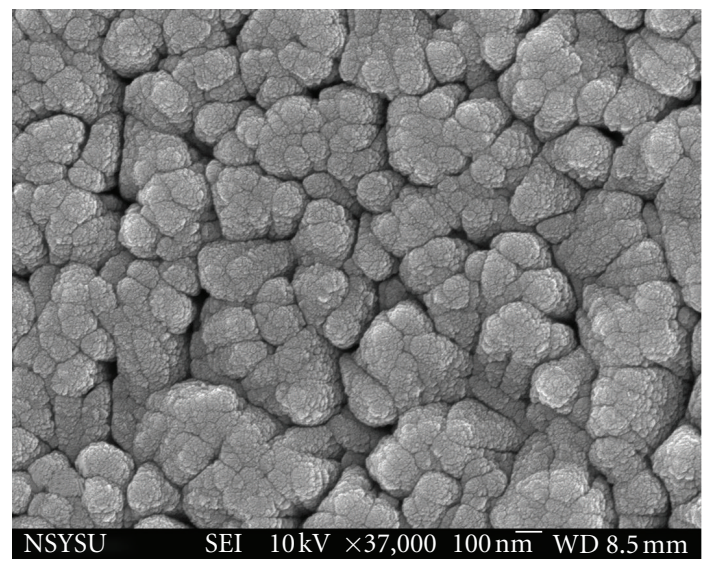

(c)

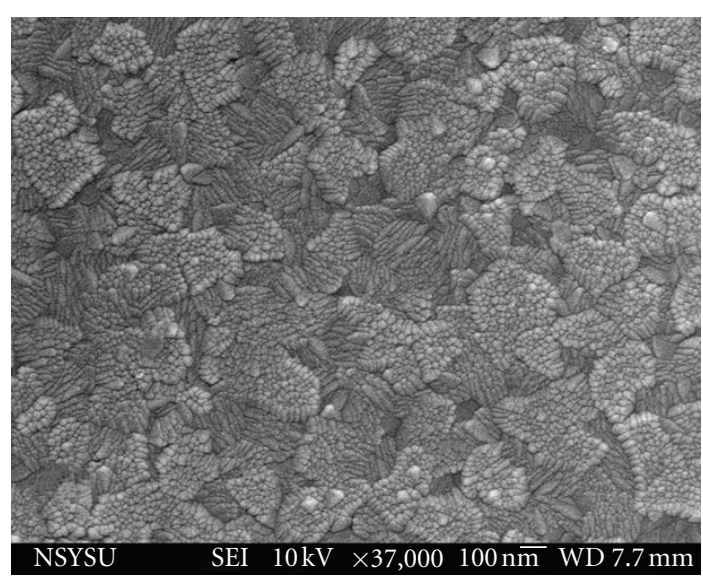

(b)

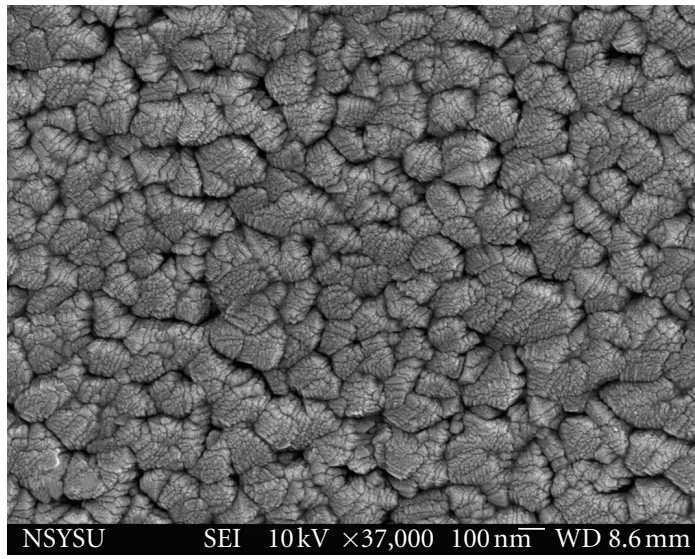

(d)

Figure 3: Plain view of SEM images of: (a) N,C-ITO, (b) ITO, (c) Ti/TO, and (d) N,C-TiO 2 films.

peak to shift to lower energy. Meanwhile, the atomic ratio of $\mathrm{SnO}_{2} / \mathrm{SnO}$ phase of the N,C-ITO is higher than that of the ITO indicating the formation of an $\mathrm{SnO}_{2}$-rich surface which confirms the results revealed by the XRD and Raman measurements. One can conclude that the observed red shifts in absorption and the band gap narrowing can be mostly attributed to the $\mathrm{N}$-doping, but be a little to the $\mathrm{C}$-doping of the N,C-ITO layer.

3.3. Photoelectrochemical Properties. Figure 6 shows a set of current-voltage $(I-V)$ characteristics recorded on the composite $\mathrm{Ti} / \mathrm{TO}$ electrode along with $\mathrm{N}, \mathrm{C}-\mathrm{TiO}_{2}, \mathrm{~N}, \mathrm{C}-$ ITO, and ITO film electrodes in $\mathrm{Na}_{2} \mathrm{CO}_{3}$ solution under illumination of AM 1.0 simulated solar light. The illuminated photocurrent increases sharply as the applied potential reaches $0.5 \mathrm{~V}$ and $0.3 \mathrm{~V}$ versus $\mathrm{SCE}$ on the Ti/TO and N,C-ITO, respectively. Note that there is no saturation of photocurrent observed in both two samples, which indicates efficient charge separation under illumination, while the saturation of photocurrent can be seen on the $\mathrm{N}, \mathrm{C}-\mathrm{TiO}_{2}$ electrode at a typical applied potential of $0.3 \mathrm{~V}$ versus SCE. Under illumination, however, the ITO substrate exhibits no gain of photocurrent with a breakdown point at about $0.9 \mathrm{~V}$ versus SCE. This indicates that the $\mathrm{N}$ and $\mathrm{C}$ dopants can enhance the PEC properties of pristine ITO film. That is, a shift of the flat band (onset) potential from -0.7 to $-0.82 \mathrm{~V}$ versus SCE is achieved by using the intercalated N,C-ITO layer, which can be estimated from the $I-V$ measurements in the PEC test [52]. Under solar light illumination, a relatively high photoactive response of the $\mathrm{Ti} / \mathrm{TO}$ electrode is attributable to, at least in part, the synergetic effect of N,Ccodoping on band gap narrowing [25] and photosensitizing [47]. Moreover, the $\mathrm{N}, \mathrm{C}-\mathrm{TiO}_{2}$ layer ( $400 \mathrm{~nm}$ thick) enhances not only the photocurrent response of the layered Ti/TO electrode at the entire applied potentials, but also the flat band (onset) potential from -0.82 to $-0.91 \mathrm{~V}$ versus SCE; a shift of negative flat band potential is desired for facilitating the PEC process $[10,52]$.

Under irradiation of AM 1.0 simulated solar light and $1.5 \mathrm{~V}$ applied bias, the layered Ti/TO film electrode has the highest photocurrent density of $0.47 \mathrm{~mA} \mathrm{~cm}^{-2}$, that is, a gain of $0.42 \mathrm{~mA} \mathrm{~cm}^{-2}$, and a hydrogen yield rate of $28.8 \mu \mathrm{mol} \mathrm{cm}^{-2} \mathrm{~h}^{-1}$ in $4.0 \mathrm{~N} \mathrm{Na}_{2} \mathrm{CO}_{3}$ solution $(\mathrm{pH} \sim 11)$, as shown in Figure 6 and Table 1. Comparatively, the N,CITO electrode has a photocurrent density of $0.46 \mathrm{~mA} \mathrm{~cm}^{-2}$, 


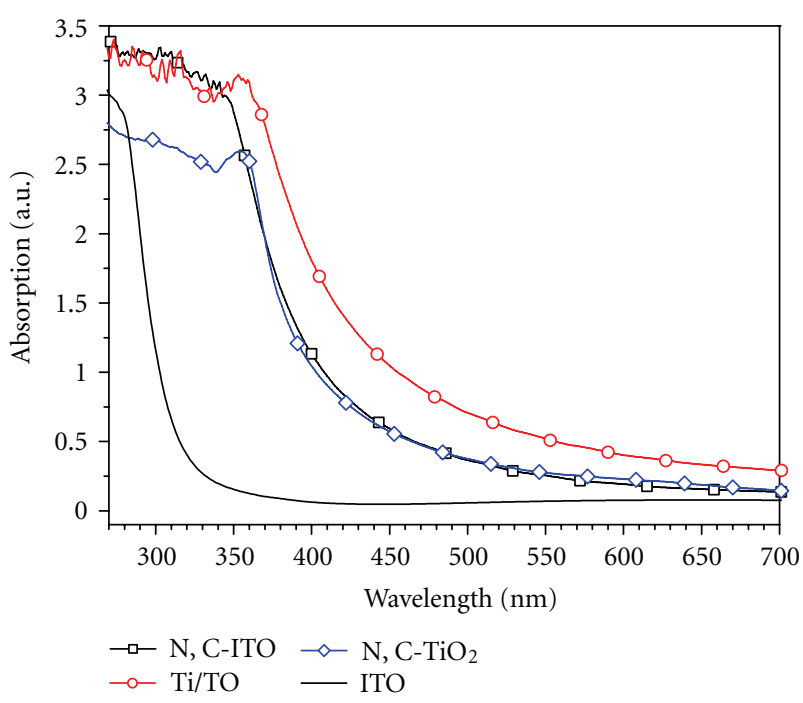

Figure 4: Absorption spectra of the composite Ti/TO electrode along with $\mathrm{N}, \mathrm{C}-\mathrm{TiO}_{2}, \mathrm{~N}, \mathrm{C}-\mathrm{ITO}$ and ITO film electrodes.

TABLE 2: Hydrogen yield rates and degradation rate constants of the $\mathrm{Ti} / \mathrm{TO}$ and $\mathrm{N}, \mathrm{C}-\mathrm{TiO}_{2}$ electrodes under illumination of $\mathrm{AM} 1.0$ stimulated solar light.

\begin{tabular}{lcccc}
\hline sample & \multicolumn{2}{c}{$\begin{array}{l}\mathrm{H}_{2} \text { yield rate, } \\
\mu \mathrm{mol} \mathrm{cm}^{-2} \mathrm{~h}^{-1}\end{array}$} & \multicolumn{2}{c}{$\begin{array}{c}\text { DMSO rate constant, } \\
\mathrm{cm}^{-2} \mathrm{~h}^{-1}\end{array}$} \\
& $0.5 \mathrm{~V}$ & $1.5 \mathrm{~V}$ & $0.5 \mathrm{~V}$ & $1.5 \mathrm{~V}$ \\
\hline $\mathrm{N}, \mathrm{C}-\mathrm{TiO}_{2}$ & 10.2 & 11.8 & $12.5 \times 10^{-3}$ & $12.8 \times 10^{-3}$ \\
$\mathrm{Ti} / \mathrm{TO}$ & 0.3 & 12.0 & $10.8 \times 10^{-3}$ & $12.6 \times 10^{-3}$ \\
\hline
\end{tabular}

that is, a gain of only $0.35 \mathrm{~mA} \mathrm{~cm}^{-2}$, and a hydrogen yield rate of $24.6 \mu \mathrm{mol} \mathrm{cm}{ }^{-2} \mathrm{~h}^{-1}$, respectively. However, the $\mathrm{N}, \mathrm{C}-\mathrm{TiO}_{2}$ electrode exhibits a photocurrent density of $0.09 \mathrm{~mA} \mathrm{~cm}^{-2}$ and a relatively high hydrogen yield rate of $25.0 \mu \mathrm{mol} \mathrm{cm}^{-2} \mathrm{~h}^{-1}$, respectively.

The PEC activity of the Ti/TO and $\mathrm{N}, \mathrm{C}-\mathrm{TiO}_{2}$ electrodes was further evaluated by degrading DMSO pollutant maxed in $\mathrm{Na}_{2} \mathrm{CO}_{3}$ aqueous solution with simultaneous hydrogen production under irradiation of AM 1.0 simulated solar light. As shown in Figure 7 and Table 2, the hydrogen yield rate obtained at $1.5 \mathrm{~V}$ is $12.0 \mu \mathrm{mol} \mathrm{cm}{ }^{-2} \mathrm{~h}^{-1}$, about 40 times higher than that $\left(0.3 \mu \mathrm{mol} \mathrm{cm}{ }^{-2} \mathrm{~h}^{-1}\right)$ at $0.5 \mathrm{~V}$ versus SCE, which is correlated well with a sharp increase in a photocurrent density of $0.65 \mathrm{~mA} \mathrm{~cm}^{-2}$, that is, a gain of $0.61 \mathrm{~mA} \mathrm{~cm}^{-2}$, at $1.5 \mathrm{~V}$ versus SCE. Under illumination of AM 1.0 simulated solar light, the degrading rate constant of DMSO is equal to $10.8 \times 10^{-3} \mathrm{~cm}^{-2} \mathrm{~h}^{-1}$ and $12.6 \times 10^{-3} \mathrm{~cm}^{-2} \mathrm{~h}^{-1}$ at an applied bias of $0.5 \mathrm{~V}$ and $1.5 \mathrm{~V}$ versus SCE, respectively. In other words, only a $17 \%$ increase in degradation rate constant is gained as the applied bias was raised from $0.5 \mathrm{~V}$ to $1.5 \mathrm{~V}$, but a $50 \%$ increase in degradation rate constant was obtained from photocatalytic $\left(7.2 \times 10^{-3} \mathrm{~cm}^{-2} \mathrm{~h}^{-1}\right)$ to PEC reaction at $0.5 \mathrm{~V}$. The $\mathrm{N}, \mathrm{C}-\mathrm{TiO}_{2}$ electrode yields about the same hydrogen evolution of $11.8 \mu \mathrm{mol} \mathrm{cm}^{-2} \mathrm{~h}^{-1}$ at $1.5 \mathrm{~V}$ versus SCE as the Ti/TO, whereas it evolves a hydrogen yield rate of $10.2 \mu \mathrm{mol} \mathrm{cm}{ }^{-2} \mathrm{~h}^{-1}$ at $0.5 \mathrm{~V}$ versus SCE which is much greater-34 times-than the Ti/TO. This is in accordance with the photocurrent density of the $\mathrm{N}, \mathrm{C}-\mathrm{TiO}_{2}$ electrode displayed in Figure 7. These imply that the Ti/TO electrode is preferably suitable for PEC applications with a higher applied bias and the $\mathrm{N}, \mathrm{C}-\mathrm{TiO}_{2}$ electrode is generally applicable to a wide range of applied bias.

It is known that an applied bias is used to facilitate the electron transport across the $\mathrm{TiO}_{2} / \mathrm{ITO}$ interface and the external circuit [53]. When the applied bias is sufficiently high to pull all of the excited electrons, the concentration of photogenerated holes can be the rate-determining step at the catalyst/electrolyte interface. The saturated photocurrent depends not only upon the types of catalysts and their morphology, crystal phase, and crystallinity, but also upon the types of electrolyte, organic compound, and their concentrations [53-56]. For instance, the $\mathrm{TiO}_{2}$ nanopore arrays that revealed a saturated photocurrent of 5.8 times as high as that for coated $\mathrm{TiO}_{2}$ nanofilm electrode has had 2 times as high as the coated $\mathrm{TiO}_{2}$ nanofilm electrode at an applied bias of $0.5 \mathrm{~V}$ versus SCE in PEC process for degradation of aqueous tetracycline solution [56]. This indicates that upon an applied bias on the high photocurrentsaturated electrode, the separation and transport efficiency of photogenerated electron/hole pairs is much higher than that for the conventional coated $\mathrm{TiO}_{2}$ electrode. This implies that the higher the saturated photocurrent is, the greater the photocatalytic oxidation and the better the efficiency can be rationally expected [54]. However, the reasons for this unexpected low increase in the DMSO rate constant of the Ti/TO electrode are not clear yet and further investigation is being undertaken in our lab.

\section{Conclusion}

The Ti/TO film electrode that combines a versatile layer of $\mathrm{N}, \mathrm{C}-\mathrm{TiO}_{2}$ and a novel intercalated layer of N,C-ITO reveals a synergetic photocatalytic capability for simultaneous DMSO degradation and hydrogen production. The structural properties of the sample electrodes, determined by X-ray diffraction (XRD) and Raman scattering, show that the overlaid $\mathrm{N}, \mathrm{C}-\mathrm{TiO}_{2}$ film exhibits primarily the crystallized anatase $\mathrm{TiO}_{2}$ phase and the intercalated N,C-ITO film shows distinct diffraction patterns of polycrystalline $\mathrm{In}_{2} \mathrm{O}_{3}$ phase. Under AM 1.0 simulated solar light irradiation and $1.5 \mathrm{~V}$ applied potential, the photocurrent density of the Ti/TO film electrode is $20 \%$ and 4.7 times higher than that of the N,C-ITO and N,C-TiO 2 electrodes, respectively. Moreover, the Ti/TO electrode yields simultaneously a hydrogen production rate of $12.0 \mu \mathrm{mol} \mathrm{cm}^{-2} \mathrm{~h}^{-1}$ and degradation rate constant of $12.6 \times 10^{-3} \mathrm{~cm}^{-2} \mathrm{~h}^{-1}$, whereas the N,CITO electrode shows no pollutant oxidation. In view of the synergetic effect of N,C-codoping on the composite Ti/TO electrode, not only the $\mathrm{N}, \mathrm{C}-\mathrm{TiO}_{2}$ layer enhances the photocurrent response and a cathode shift of the flat band potential, but also the intercalated N,C-ITO layer can significantly increase photocurrent response at a high applied potential. These are desperately beneficial in the PEC process of pollutant degradation and hydrogen production as well. 


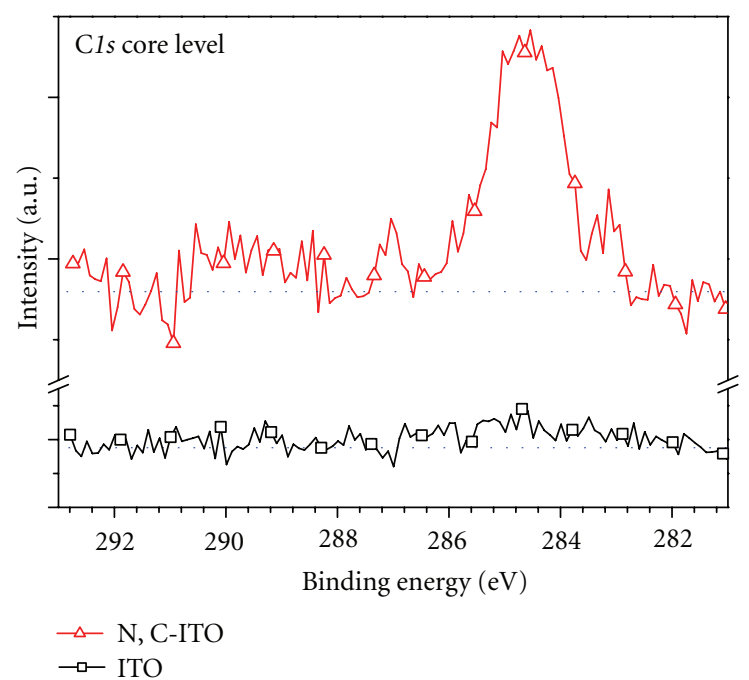

(a)

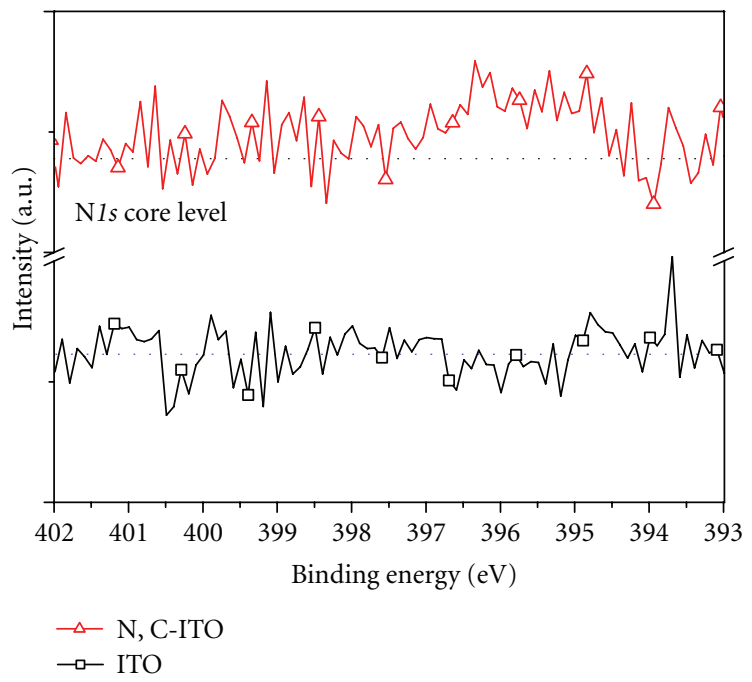

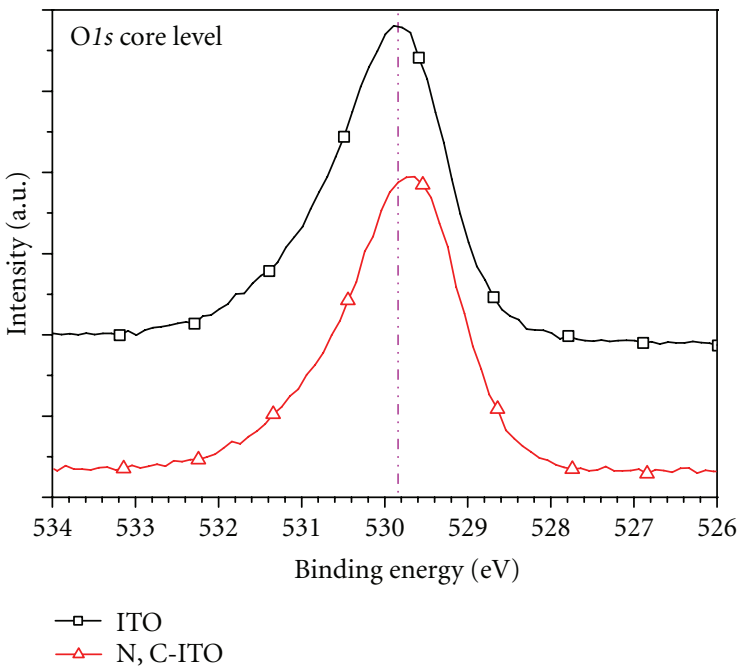

(b)

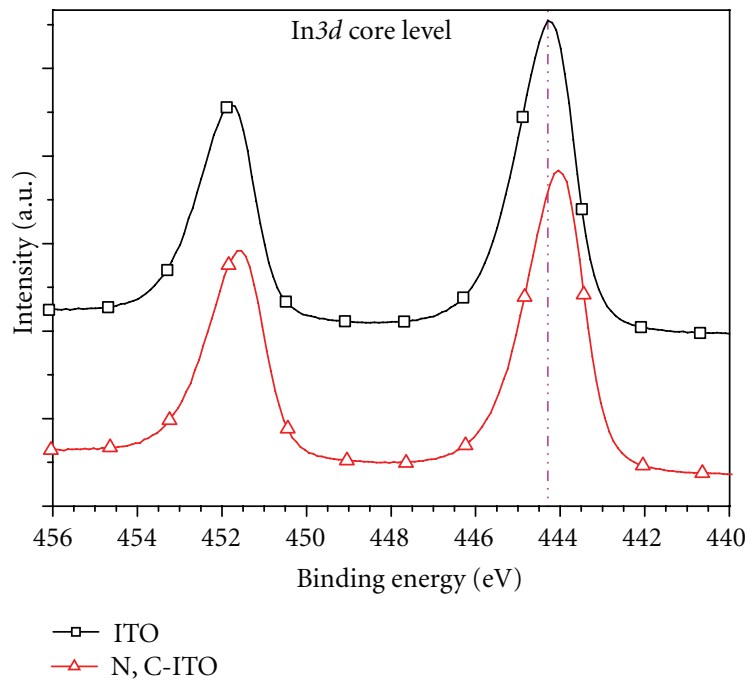

(d)

(c)

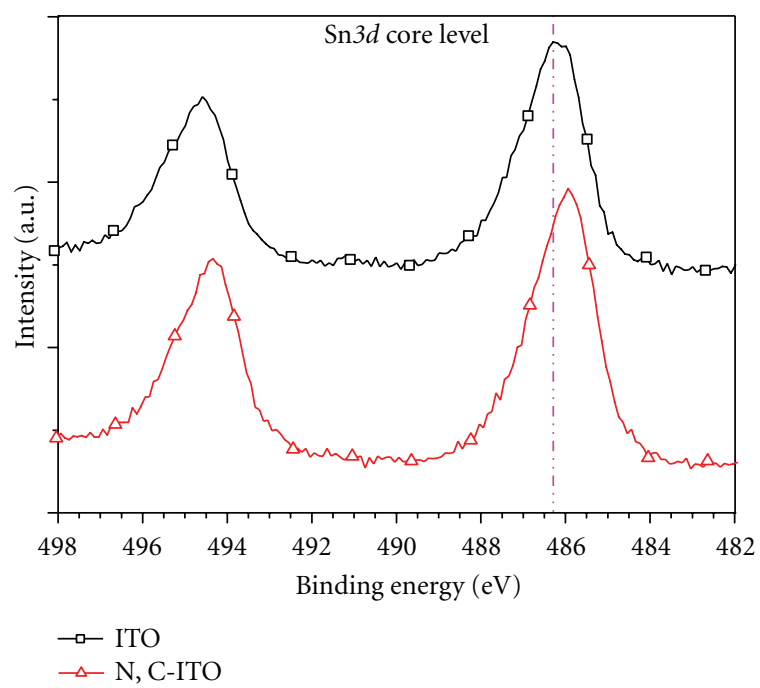

(e)

Figure 5: XPS high-resolution spectra of: (a) C1s, (b) O1s, (c) N1s, (d) In3d, and (e) Sn3d core levels for the N,C-ITO and ITO film electrodes. 


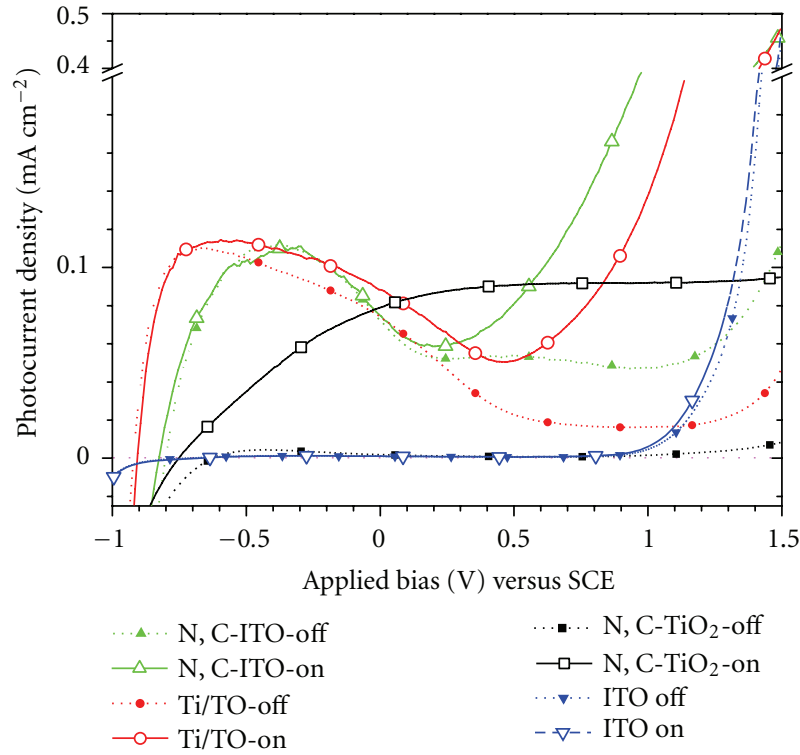

Figure 6: Photocurrent response of the Ti/TO and $\mathrm{N}, \mathrm{C}-\mathrm{TiO}_{2}$ electrodes along with $\mathrm{N}, \mathrm{C}$-ITO and ITO substrates in $\mathrm{Na}_{2} \mathrm{CO}_{3}$ solution.

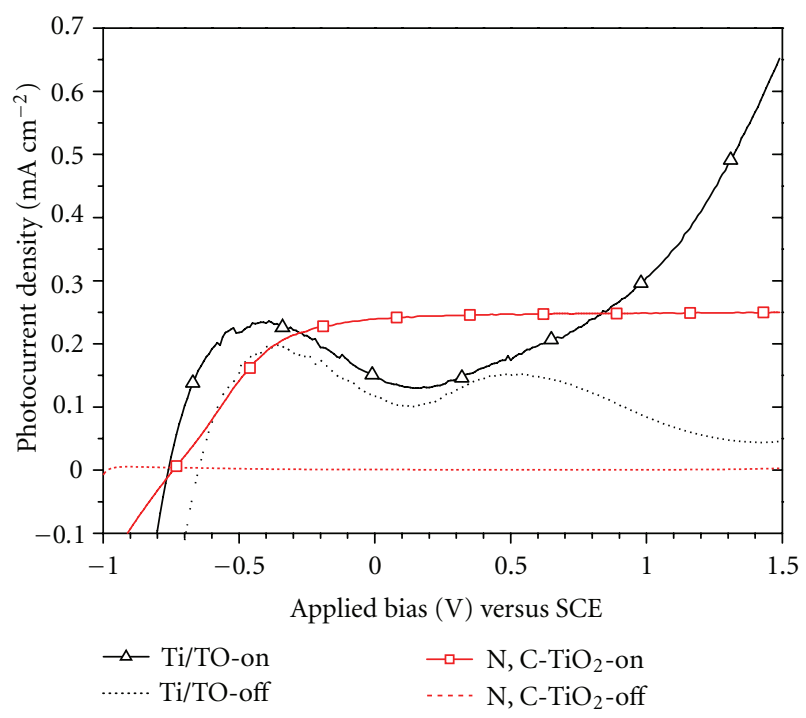

Figure 7: Photocurrent response of the Ti/TO and N,C-TiO electrodes in $\mathrm{Na}_{2} \mathrm{CO}_{3}$ mixed with DMSO aqueous solution.

\section{Acknowledgment}

The authors would like to thank the National Science Council of Taiwan, for financially supporting this research under Contract no. NSC 98-2221-E-022-004-MY2.

\section{References}

[1] T. Bak, J. Nowotny, M. Rekas, and C. C. Sorrell, "Photoelectrochemical hydrogen generation from water using solar energy. Materials-related aspects," International Journal of Hydrogen Energy, vol. 27, no. 10, pp. 991-1022, 2002.
[2] B. Marsen, E. L. Miller, D. Paluselli, and R. E. Rocheleau, "Progress in sputtered tungsten trioxide for photoelectrode applications," International Journal of Hydrogen Energy, vol. 32, no. 15, pp. 3110-3115, 2007.

[3] J. Yu and J. Ran, "Facile preparation and enhanced photocatalytic $\mathrm{H} 2$-production activity of $\mathrm{Cu}(\mathrm{OH}) 2$ cluster modified $\mathrm{TiO}_{2}$," Energy and Environmental Science, vol. 4, no. 4, pp. 1364-1371, 2011.

[4] A. Fujishima and K. Honda, "Electrochemical photolysis of water at a semiconductor electrode," Nature, vol. 238, no. 5358, pp. 37-38, 1972.

[5] A. Patsoura, D. I. Kondarides, and X. E. Verykios, "Enhancement of photoinduced hydrogen production from irradiated $\mathrm{Pt} / \mathrm{TiO}_{2}$ suspensions with simultaneous degradation of azodyes," Applied Catalysis B, vol. 64, no. 3-4, pp. 171-179, 2006.

[6] M. Kaneko, H. Ueno, K. Ohnuki, M. Horikawa, R. Saito, and J. Nemoto, "Direct electrical power generation from urine, wastes and biomass with simultaneous photodecomposition and cleaning," Biosensors and Bioelectronics, vol. 23, no. 1, pp. 140-143, 2007.

[7] D. I. Kondarides, V. M. Daskalaki, A. Patsoura, and X. E. Verykios, "Hydrogen production by photo-induced reforming of biomass components and derivatives at ambient conditions," Catalysis Letters, vol. 122, no. 1-2, pp. 26-32, 2008.

[8] M. Antoniadou, P. Bouras, N. Strataki, and P. Lianos, "Hydrogen and electricity generation by photoelectrochemical decomposition of ethanol over nanocrystalline titania," International Journal of Hydrogen Energy, vol. 33, no. 19, pp. 50455051, 2008.

[9] H. Park, A. Bak, Y. Y. Ahn, J. Choi, and M. R. Hoffmannn, "Photoelectrochemical performance of multi-layered $\mathrm{BiO}_{x}-$ $\mathrm{TiO}_{2} / \mathrm{Ti}$ electrodes for degradation of phenol and production of molecular hydrogen in water," Journal of Hazardous Materials. In press.

[10] J. Nowotny, T. Bak, M. K. Nowotny, and L. R. Sheppard, "Titanium dioxide for solar-hydrogen I. Functional properties," International Journal of Hydrogen Energy, vol. 32, no. 14, pp. 2609-2629, 2007.

[11] X. Yong and M. A. A. Schoonen, "The absolute energy positions of conduction and valence bands of selected semiconducting minerals," American Mineralogist, vol. 85, no. 3-4, pp. 543-556, 2000.

[12] E. L. Miller, D. Paluselli, B. Marsen, and R. E. Rocheleau, "Development of reactively sputtered metal oxide films for hydrogen-producing hybrid multijunction photoelectrodes," Solar Energy Materials and Solar Cells, vol. 88, no. 2, pp. 131$144,2005$.

[13] Z. Xu and J. Yu, "Visible-light-induced photoelectrochemical behaviors of Fe-modified $\mathrm{TiO}_{2}$ nanotube arrays," Nanoscale, vol. 3, no. 8, pp. 3138-3144, 2011.

[14] Y. Ma, J. B. Qiu, Y. A. Cao, Z. S. Guan, and J. N. Yao, "Photocatalytic activity of $\mathrm{TiO}_{2}$ films grown on different substrates," Chemosphere, vol. 44, no. 5, pp. 1087-1092, 2001.

[15] H. Irie, H. Mori, and K. Hashimoto, "Interfacial structure dependence of layered $\mathrm{TiO}_{2} / \mathrm{WO}_{3}$ thin films on the photoinduced hydrophilic property," Vacuum, vol. 74, no. 3-4, pp. 625-629, 2004.

[16] W. Dai, X. Wang, P. Liu, Y. Xu, G. Li, and X. Fu, "Effects of electron transfer between $\mathrm{TiO}_{2}$ films and conducting substrates on the photocatalytic oxidation of organic pollutants," Journal of Physical Chemistry B, vol. 110, no. 27, pp. 13470-13476, 2006.

[17] H. Chen, S. Chen, X. Quan, H. Yu, H. Zhao, and Y. Zhang, "Fabrication of $\mathrm{TiO}_{2}-\mathrm{Pt}$ coaxial nanotube array Schottky structures for enhanced photocatalytic degradation of phenol 
in aqueous solution," Journal of Physical Chemistry C, vol. 112, no. 25, pp. 9285-9290, 2008.

[18] J. Bai, J. Li, Y. Liu, B. Zhou, and W. Cai, "A new glass substrate photoelectrocatalytic electrode for efficient visiblelight hydrogen production: CdS sensitized $\mathrm{TiO}_{2}$ nanotube arrays," Applied Catalysis B, vol. 95, no. 3-4, pp. 408-413, 2010.

[19] J. R. Sheats, H. Antoniadis, M. Hueschen et al., "Organic electroluminescent devices," Science, vol. 273, no. 5277, pp. 884-888, 1996.

[20] A. J. Nozik and R. Memming, "Physical chemistry of semiconductor-liquid interfaces," Journal of Physical Chemistry, vol. 100, no. 31, pp. 13061-13078, 1996.

[21] A. Fujishima, T. N. Rao, and D. A. Tryk, "Titanium dioxide photocatalysis," Journal of Photochemistry and Photobiology C, vol. 1, no. 1, pp. 1-21, 2000.

[22] J. Gamage and Z. Zhang, "Applications of photocatalytic disinfection," International Journal of Photoenergy, vol. 2010, Article ID 764870, 11 pages, 2010.

[23] J. A. Byrne, P. A. Fernandez-Ibañez, P. S.M. Dunlop, D. M.A. Alrousan, and J. W.J. Hamilton, "Photocatalytic enhancement for solar disinfection of water: a review," International Journal of Photoenergy, vol. 2011, Article ID 798051, 12 pages, 2011.

[24] T. Sano, N. Negishi, K. Koike, K. Takeuchi, and S. Matsuzawa, "Preparation of a visible light-responsive photocatalyst from a complex of $\mathrm{Ti}^{4+}$ with a nitrogen-containing ligand," Journal of Materials Chemistry, vol. 14, no. 3, pp. 380-384, 2004.

[25] D. Noguchi, Y. Kawamata, and T. Nagatomo, "The response of $\mathrm{TiO}_{2}$ photocatalysts codoped with nitrogen and carbon to visible light," Journal of the Electrochemical Society, vol. 152, no. 9, pp. D124-D129, 2005.

[26] Q. Li, R. Xie, W. L. Yin, E. A. Mintz, and K. S. Jian, "Enhanced visible-light-induced photocatalytic disinfection of E. coli by carbon-sensitized nitrogen-doped titanium oxide," Environmental Science and Technology, vol. 41, no. 14, pp. 5050-5056, 2007.

[27] S. Yin, M. Komatsu, Q. Zhang, F. Saito, and T. Sato, "Synthesis of visible-light responsive nitrogen/carbon doped titania photocatalyst by mechanochemical doping," Journal of Materials Science, vol. 42, no. 7, pp. 2399-2404, 2007.

[28] K. R. Wu and C. H. Hung, "Characterization of N,C-codoped $\mathrm{TiO}_{2}$ films prepared by reactive DC magnetron sputtering," Applied Surface Science, vol. 256, no. 5, pp. 1595-1603, 2009.

[29] Q. Xiang, J. Yu, W. Wang, and M. Jaroniec, "Nitrogen self-doped nanosized $\mathrm{TiO}_{2}$ sheets with exposed 001 facets for enhanced visible-light photocatalytic activity," Chemical Communications, vol. 47, no. 24, pp. 6906-6908, 2011.

[30] H. Fu, G. Shang, S. Yang, and T. Xu, "Mechanistic study of visible-light-induced photodegradation of 4-chlorophenol by $\mathrm{TiO}_{2}-\mathrm{x} \mathrm{Nx}$ with low nitrogen concentration," International Journal of Photoenergy, vol. 2012, Article ID 759306, 9 pages, 2012.

[31] K. R. Reyes-Gil, E. A. Reyes-García, and D. Raftery, "Nitrogendoped $\mathrm{in}_{2} \mathrm{O}_{3}$ thin film electrodes for photocatalytic water splitting," Journal of Physical Chemistry C, vol. 111, no. 39, pp. 14579-14588, 2007.

[32] K. R. Wu, C. W. Yeh, C. H. Hung, L. H. Cheng, and C. Y. Chung, "Photoelectrochemical properties of nitrogendoped indium tin oxide thin films prepared by reactive DC magnetron sputtering," Thin Solid Films, vol. 518, no. 5, pp. 1581-1584, 2009.

[33] Y. Sun, C. J. Murphy, K. R. Reyes-Gil, E. A. Reyes-Garcia, J. P. Lilly, and D. Raftery, "Carbon-doped $\operatorname{in}_{2} \mathrm{O}_{3}$ films for photoelectrochemical hydrogen production," International Journal of Hydrogen Energy, vol. 33, no. 21, pp. 5967-5974, 2008.
[34] M. H. Habibi and N. Talebian, "Photocatalytic degradation of an azo dye X6G in water: a comparative study using nanostructured indium tin oxide and titanium oxide thin films," Dyes and Pigments, vol. 73, no. 2, pp. 186-194, 2007.

[35] Y. Bessekhouad, D. Robert, and J. V. Weber, "Bi2S3/TiO 2 and $\mathrm{CdS} / \mathrm{TiO}_{2}$ heterojunctions as an available configuration for photocatalytic degradation of organic pollutant," Journal of Photochemistry and Photobiology A, vol. 163, no. 3, pp. 569580, 2004.

[36] K. R. Wu, C. H. Hung, C. W. Yeh, C. C. Wang, and T. P. Cho, The TechConnect World, Paper No. 545, Anaheim, Calif, USA, 2010.

[37] S. Matsui, Y. Okawa, and R. Ota, “Experience of 16 years' operation and maintenance of the Fukashiba industrial wastewater treatment plant of the Kashima petrochemical complexII. Biodegradability of 37 organic substances and 28 process wastewaters," Water Science and Technology, vol. 20, no. 10, pp. 201-210, 1988.

[38] S.-J. Park, T.-I. Yoon, J.-H. Bae, H.-J. Seo, and H.-J. Park, "Biological treatment of wastewater containing dimethyl sulphoxide from the semi-conductor industry," Process Biochemistry, vol. 36, no. 6, pp. 579-589, 2001.

[39] Y. Lee, C. Lee, and J. Yoon, "Kinetics and mechanisms of DMSO (dimethylsulfoxide) degradation by $\mathrm{UV} / \mathrm{H}_{2} \mathrm{O}_{2}$ process," Water Research, vol. 38, no. 10, pp. 2579-2588, 2004.

[40] J. J. Wu, M. Muruganandham, and S. H. Chen, "Degradation of DMSO by ozone-based advanced oxidation processes," Journal of Hazardous Materials, vol. 149, no. 1, pp. 218-225, 2007.

[41] C. Lee, Y. Lee, and J. Yoon, "Oxidative degradation of dimethylsulfoxide by locally concentrated hydroxyl radicals in streamer corona discharge process," Chemosphere, vol. 65, no. 7, pp. 1163-1170, 2006.

[42] M. N. Abellán, R. Dillert, J. Giménez, and D. Bahnemann, "Evaluation of two types of $\mathrm{TiO}_{2}$-based catalysts by photodegradation of DMSO in aqueous suspension," Journal of Photochemistry and Photobiology A, vol. 202, no. 2-3, pp. 164$171,2009$.

[43] S. Ngamsinlapasathian, T. Sreethawong, Y. Suzuki, and S. Yoshikawa, "Doubled layered $\mathrm{ITO} / \mathrm{SnO}_{2}$ conducting glass for substrate of dye-sensitized solar cells," Solar Energy Materials and Solar Cells, vol. 90, no. 14, pp. 2129-2140, 2006.

[44] M. Kamei, Y. Shigesato, and S. Takaki, "Origin of characteristic grain-subgrain structure of tin-doped indium oxide films," Thin Solid Films, vol. 259, no. 1, pp. 38-45, 1995.

[45] N. Nadaud, N. Lequeux, M. Nanot, J. Jové, and T. Roisnel, "Structural studies of tin-doped indium oxide (ITO) and $\mathrm{In}_{4} \mathrm{Sn}_{3} \mathrm{O}_{12}$," Journal of Solid State Chemistry, vol. 135, no. 1, pp. 140-148, 1998.

[46] V. Swamy, A. Kuznetsov, L. S. Dubrovinsky, R. A. Caruso, D. G. Shchukin, and B. C. Muddle, "Finite-size and pressure effects on the Raman spectrum of nanocrystalline anatase $\mathrm{TiO}_{2}$," Physical Review B, vol. 71, no. 18, Article ID 184302, 2005.

[47] S. W. Hsu, T. S. Yang, T. K. Chen, and M. S. Wong, "Ionassisted electron-beam evaporation of carbon-doped titanium oxide films as visible-light photocatalyst," Thin Solid Films, vol. 515, no. 7-8, pp. 3521-3526, 2007.

[48] R. Asahi and T. Morikawa, "Nitrogen complex species and its chemical nature in $\mathrm{TiO}_{2}$ for visible-light sensitized photocatalysis," Chemical Physics, vol. 339, no. 1-3, pp. 57-63, 2007.

[49] S. Yin, M. Komatsu, Q. Zhang, F. Saito, and T. Sato, "Synthesis of visible-light responsive nitrogen/carbon doped titania photocatalyst by mechanochemical doping," Journal of Materials Science, vol. 42, no. 7, pp. 2399-2404, 2007. 
[50] C. Nunes De Carvalho, A. M. Botelho Do Rego, A. Amaral, P. Brogueira, and G. Lavareda, "Effect of substrate temperature on the surface structure, composition and morphology of indium-tin oxide films," Surface and Coatings Technology, vol. 124, no. 1, pp. 70-75, 2000.

[51] Y. Inoue, M. Nomiya, and O. Takai, "Physical properties of reactive sputtered tin-nitride thin films," Vacuum, vol. 51, no. 4, pp. 673-676, 1998.

[52] M. Radecka, M. Rekas, A. Trenczek-Zajac, and K. Zakrzewska, "Importance of the band gap energy and flat band potential for application of modified $\mathrm{TiO}_{2}$ photoanodes in water photolysis," Journal of Power Sources, vol. 181, no. 1, pp. 4655, 2008.

[53] D. Jiang, H. Zhao, S. Zhang, and R. John, "Comparison of photocatalytic degradation kinetic characteristics of different organic compounds at anatase $\mathrm{TiO}_{2}$ nanoporous film electrodes," Journal of Photochemistry and Photobiology A, vol. 177, no. 2-3, pp. 253-260, 2006.

[54] M. Park, A. Heo, E. Shim, J. Yoon, H. Kim, and H. Joo, "Effect of length of anodized $\mathrm{TiO}_{2}$ tubes on photoreactivity: photocurrent, $\mathrm{Cr}(\mathrm{VI})$ reduction and $\mathrm{H}_{2}$ evolution," Journal of Power Sources, vol. 195, no. 15, pp. 5144-5149, 2010.

[55] Y. Liu, B. Zhou, J. Li, X. Gan, J. Bai, and W. Cai, "Preparation of short, robust and highly ordered $\mathrm{TiO}_{2}$ nanotube arrays and their applications as electrode," Applied Catalysis B, vol. 92, no. 3-4, pp. 326-332, 2009.

[56] Y. Liu, X. Gan, B. Zhou et al., "Photoelectrocatalytic degradation of tetracycline by highly effective $\mathrm{TiO}_{2}$ nanopore arrays electrode," Journal of Hazardous Materials, vol. 171, no. 1-3, pp. 678-683, 2009. 


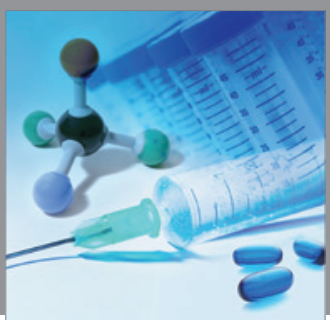

International Journal of

Medicinal Chemistry

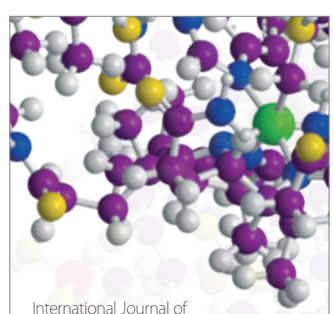

Carbohydrate Chemistry

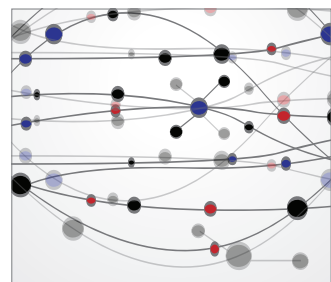

The Scientific World Journal
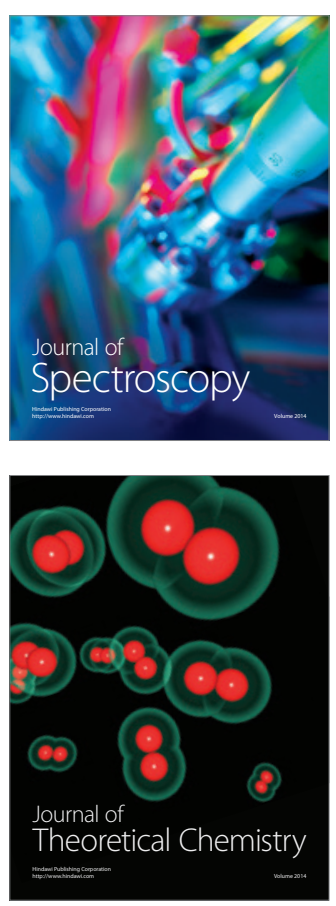
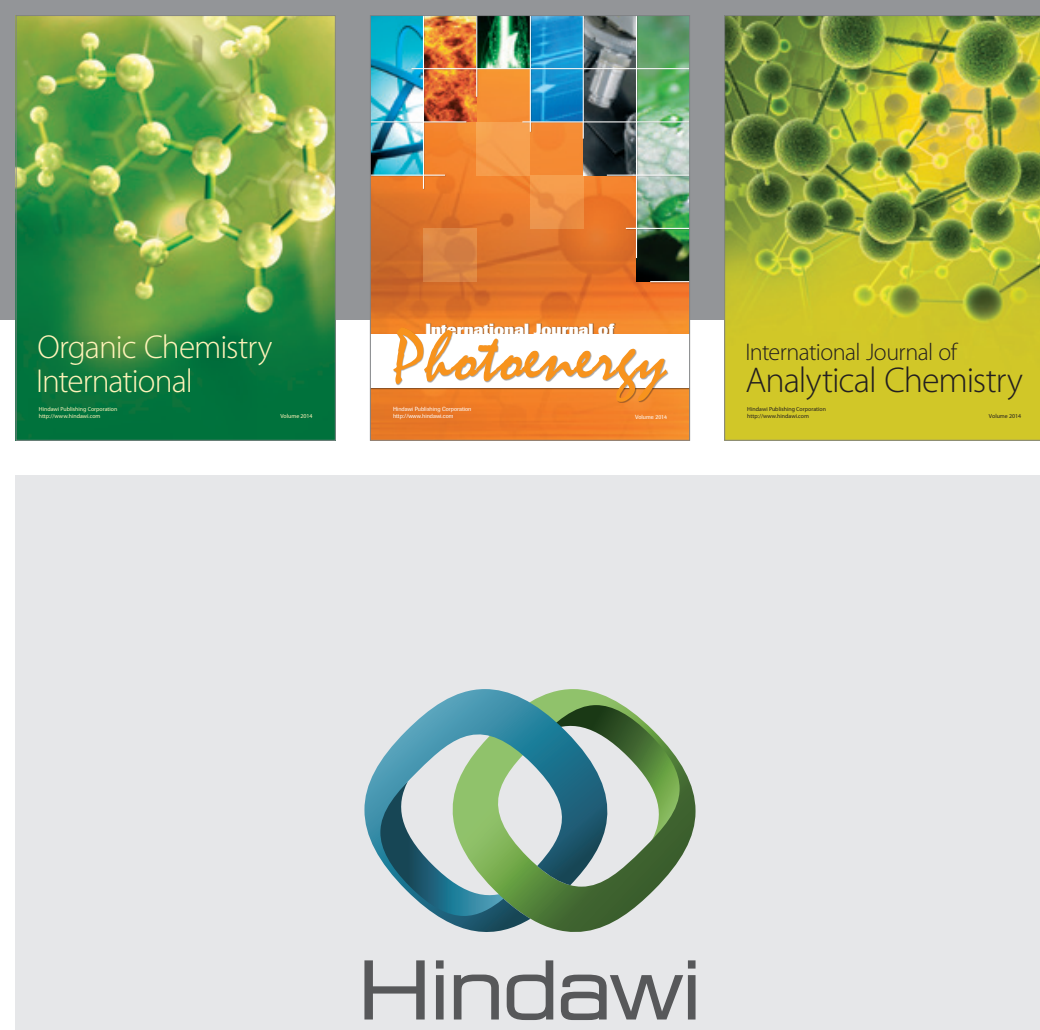

Submit your manuscripts at

http://www.hindawi.com
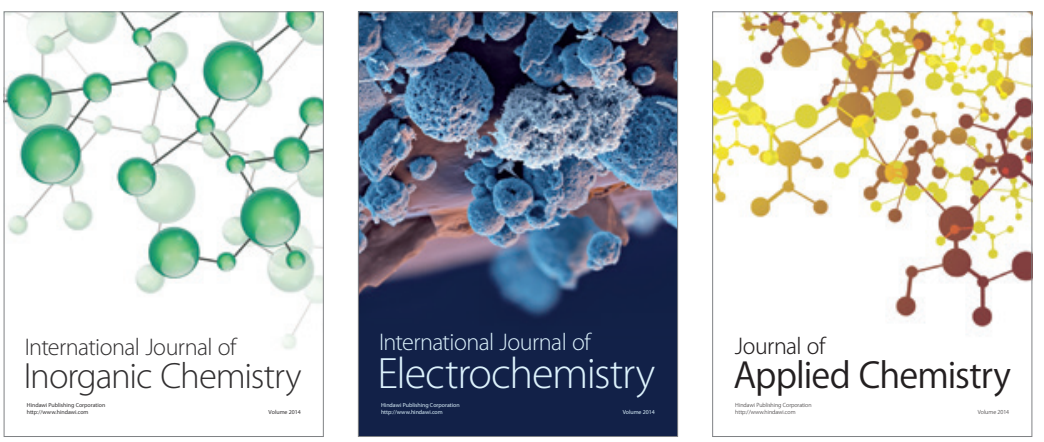

Journal of

Applied Chemistry
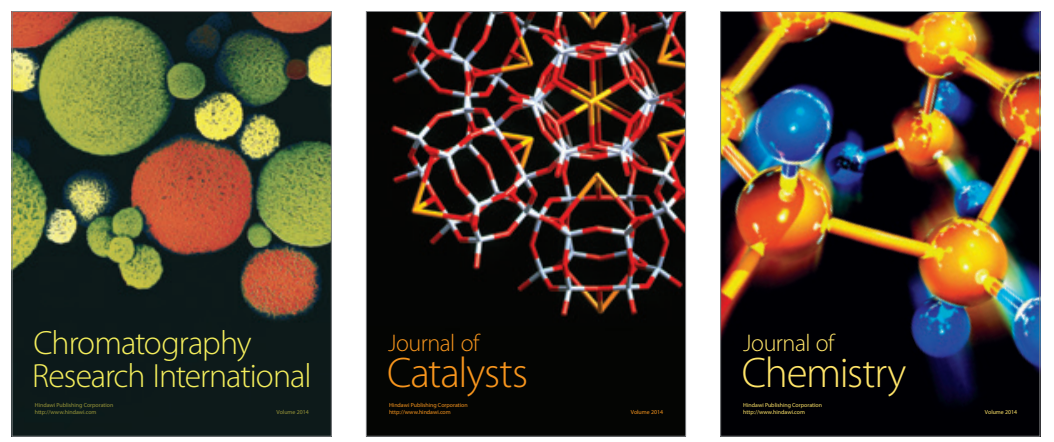
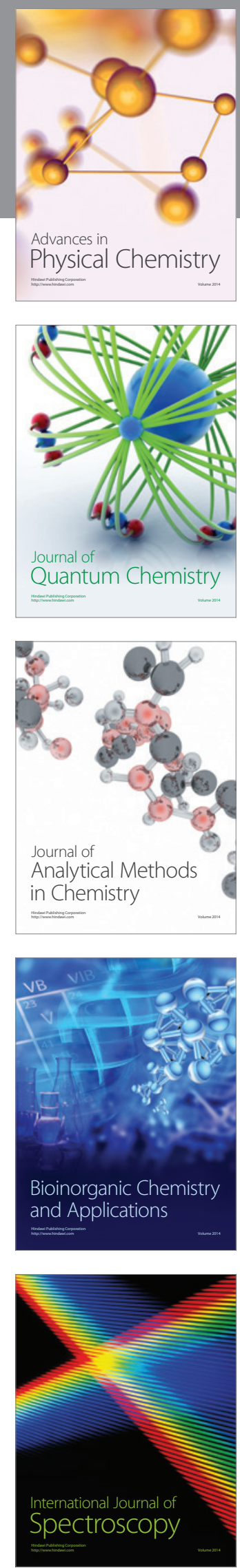